\title{
Two-sided Network Effects and Competitive Balance in Professional Team Sports
}

\author{
By \\ Sang Hoo Bae* and Jiyoung Kwon**
}

February 18, 2008

\begin{abstract}
This paper analyzes issues associated with network effects and two-sidedness in the market for professional team sports. Teams in professional sports leagues have to compete both for players (inputs) and fans (consumers). In this setting, we construct a theoretical framework where fans are more attracted to a team with a large portion of talented players from a fixed talent pool, at the same time that players want to show their ability in front of a large number of fans. We observe that either perfect imbalance or alleviated imbalance will prevail as an equilibrium. The outcome depends upon the relative magnitude of two opposite effects, the product differentiation effect and the wage reduction effect caused by externalities from the size of talented players and fans respectively. Furthermore, we incorporate asymmetric relative quality effects into consumers' utility in order to analyze its impact on competitive balance. This is shown to either exacerbate or improve the imbalanced distribution of talented players, depending on fans' sensitivity to the relative quality between teams. The policy implications of revenue sharing on competitive balance and the level of wage offers under the condition of two-sided network effects are analyzed.
\end{abstract}

JEL Classification: L83, L14, L15.

Keywords: Network externality, Two-sided market, Competitive balance,

Revenue sharing, Sports economics.

*Sang Hoo Bae (Corresponding Author)

Department of Economics, Clark University

Worcester, MA 01610

E-mail:sbae@clarku.edu

** Jiyoung Kwon

Department of Economics, University of North Texas

Denton, TX 76203

E-mail: kwon@unt.edu

We are grateful to Anthony Creane, Roger Noll, Stefan Szymanski and participants in seminars at Clark University, Northeastern University, Suffolk University, IIOC(2005) and WEAI (2007) Conference for constructive comments and encouragement. Any remaining errors are solely ours. 


\section{Introduction}

One of key elements to the success of professional sports leagues is the uncertainty of the outcome of games. The more predictable the outcome gets, the less fans are attracted to games in the sports league. Rottenberg (1957) argues that the in professional competitive sport industry, teams will usually prefer winning to losing and will also prefer winning by close margins to winning by wide margins. He also argues that professional competitive sports would be more successful if talented players are approximately equally distributed among teams. To the extent that the federal courts believe that competitive balance improves social welfare, they have granted leagues limited leeway to set up rules to promote balance in each sport. Examples of such industry-wide cooperative rules include uniform game rules, schedules, and the allocation of players. Specifically, implementation of revenue sharing, salary caps and luxury tax are claimed to be pro-competitive by team owners and leagues. According to the 'uncertainty of outcome' hypothesis, this balance is crucial because the excitement due to the uncertainty of a game's outcome is a significant component in professional team sports.

This paper is closely related to the literature on two-sided markets and two-sided competition. The growing economics literature on two-sided markets is pioneered by Armstrong (2002), Caillaud and Jullien (2003) and Rochet and Tirole (2003, 2004). A market is said to be two-sided if firms serve two distinct types of customers, which depend on each other in some important way, and also increase the value of platforms through joint participation. ${ }^{1}$ A model analyzing the professional sports market must take into account the two-sided nature of this market. In addition to the fans market there is also the players market (an input market) and the two are closely related by inter-market network externalities. The key assumption in this article is that players value the number of fans, so players trade off salary versus the market size. For instance, a player would accept a lower salary offer by a large-market team. This assumption may seem to be contradicted by the previous empirical studies which show that the salary of players in large-market teams is higher than in small-market teams. (Burger and Walters (2003))

\footnotetext{
${ }^{1}$ This is the definition by Evans (2003). Rochet and Tirole (2004) use a slightly different one: for them, a necessary and sufficient condition for a market to be two-sided is that the volume of transactions be sensitive to the distribution of total costs between the two sides.
} 
The empirical results can be explained by the difference between marginal revenues of large-market teams and small-market teams. The large-market teams benefit more from winning than small-market teams, so players in large-market team can get paid more. (ElHodiri and Quirk (1971)) However, what we argue in this article is not that players in a large-market team get paid less than players in a small market team. What we assume is that a player is willing to take a lower salary offer than he/she should have deserved because he/she can enjoy extra benefits from playing for a large-market team. The extra benefits may include both monetary (endorsement deals) and non-monetary (more TV time and audiences) benefits. The value players place on more fans would be the key source of the externality. A player also can get the positive externality from a star player teammate because the star player will attract more fans. ${ }^{2}$ The reservation wages of players depends on the number of the fans, as well as fans' demand being a function of the number of talented players. In other words, a player is willing to take a lower wage offer from a team with a larger fan base than from a team with a smaller fan base, as well as fans are attracted to a team with many talented players.

The intent of this paper is to propose a theoretical model to explain the following simple research question: How does the competitive imbalance among teams occur in the first place? To answer the question we develop a simple two-team model incorporating two-sided externalities for fans and athletes but without imposing the assumption of asymmetry in terms of teams' markets size, revenue functions, etc, which is generally considered the origin of competitive imbalance. For instance, the owners of professional teams face a "two-sided market" in which fans are more attracted to a team with a larger portion of talented players from a fixed pool at the same time that players want to show their ability in front of a larger number of fans. In this setting, even with symmetric revenue function of teams, we observe that either perfect imbalance or alleviated imbalance will prevail as an equilibrium. The outcome depends upon the relative magnitude of two opposite effects, the product differentiation effect and the wage reduction effect caused by externalities from the size of talented players and fans respectively. To the best of our knowledge, we are the first study to analyze the origin of

\footnotetext{
${ }^{2}$ We do not incorporate the component of the externality from a star player teammate in our model in order to make the analysis simple.
} 
competitive imbalance without assuming asymmetry. Furthermore, we incorporate asymmetric relative quality effects into consumers' utility in order to analyze its impact on competitive balance. This is shown to either exacerbate or improve the imbalanced distribution of talented players, depending on fans' sensitivity to the relative quality between teams. The policy implications of revenue sharing on competitive balance and the level of wage offers under the condition of two-sided network effects are analyzed.

Incorporating the externality of the number of fans in the talented player's utility function we assume that talented players are homogeneous in their ability, but heterogeneous in their marginal valuation of the network externality from each team's number of fans. A player with high marginal valuation of the network externality is willing to accept less salary in order to play for a big market team. This heterogeneity assumption is convincing because some players have more desire for a big market team than the other players.

To introduce a talented player's positive externality on consumers, we assume that the quality of a team is determined by the number of talented players hired by the team, and is shown to have both the absolute and relative quality effect on consumer's preferences. The absolute quality of a team affects each consumer's valuation toward the team similar to the models of consumer's choice over products with different qualities. On the other hand, the second channel of quality is a competitive balance effect due to differences in quality among teams (i.e., the relative quality), which is assumed to be team-specific. As an example, a fan of a high-quality team with a large number of talented players may be less concerned about the quality gap compared to a fan of lowquality team with a small number of talented players. The extent to which fans associated with high-quality teams are less affected by the competitive balance effect is an empirical question, but we analyze the impact of relative quality on consumer's preference under the both scenarios with the team-specific quality-gap effects.

This paper also has other unique features compared to the previous literature on the comparative balance issue in professional team sports (El-Hodiri and Quirk 1971; Fort and Quirk 1995; Vrooman 1995; Késenne 2000; Szymanski and Késenne 2004). Previous studies have adopted contest models to analyze the impact of revenue sharing on the competitive balance in which the asymmetric nature of the contest is exogenously 
given. The underlying logic is that, due to given asymmetry among teams, self-interested team behavior will reduce competitive balance, thus revenue sharing may be required to restore competitive balance. Szymanski and Késenne (2004) argue, for instance, that teams are assumed to have symmetric effort functions, which implies that the same effort level among teams yields the same probability of winning, and the asymmetric contest stems from team-specific revenue functions. A major contribution of our paper to the literature is that the asymmetric distribution of talented player is derived from the nature of two-sided externalities and not from given asymmetry between teams.

Another distinctive feature of our paper is the modeling of the market for players. Most of the literature does not explicitly model this market. Instead, they assume a competitive market for players in which the level of salary is exogenously determined at a fixed level, implying the existence of some kind of walrasian-type market mechanism to equalize the supply and demand of talented players. ${ }^{34}$ As a result, all teams have the same marginal cost of hiring talented players. In contrast, we explicitly construct wage offer functions for talented players and the optimal salary of each team is endogenously determined at a Nash Equilibrium. The benefit of introducing an endogenous wage offer function is that our results do not rely on a "fixed supply conjectural variation" assumed by Fort and Quirk (1995). The main drawback of fixed supply conjectural variation is 'the loss of degree of freedom' where one team's choice automatically eliminates the freedom of the other team's choice in a two team model. Therefore, one team's choice actually determines the optimal share of talented players and thus yields the unrealistic result that all the marginal revenue from talented players is equalized across teams since both are assumed to have the same marginal cost of hiring talented players. ${ }^{5}$ The equalized marginal revenue of teams results in the invariance principle where team's marginal revenue is independent of the revenue sharing scheme. In this paper we are able to generate the invariance principle of the impact of revenue sharing on competitive

\footnotetext{
${ }^{3}$ Szymanski (2004) also evaluates this walrasian-type market clearing mechanism as '.. in the sense that the market-clearing price vector must be identified by some kind of "invisible hand" or "auctioneer," which is disembodied from the specific actions of any agent in the market....'

${ }^{4}$ Other equilibrium concept rather than the one in the walrasian model has been adopted: Nash-Cournot (Szymanski, 2004) and a rational expectations equilibrium (Fort and Quirk, 2007). See Fort (2006) for an extensive discussion on this issue.

${ }^{5}$ More detailed discussion about fixed supply conjectural variation see Szymanski (2004) and Szymanski and Késenne (2004).
} 
balance without assuming the fixed supply conjecture in Fort and Quirk (1995). Our result rather resides in the collusive nature of revenue sharing with two-sided network effects.

Applying two-sided market theory to the market of professional sports is viewed as an important application along with other the two-sided markets literature such as credit cards (Rochet and Tirole (2002, 2003), Schmalensee (2002), Wright (2003)), intermediaries (Caillaud and Jullien (2003), Baye and Morgan (2001)), Yellow Page directories (Rysman (2003)] and broadcasting [Anderson and Coate (2003)]. Our paper is not the first to investigate two-sided competition (Frascatore 1999; Pepall and Rechards 2001 among others). Frascatore (1999) analyzes competition for high-quality labor in a professional sports market where leagues vertically differentiate their product by competing for the fixed number of stars with discrete talent. Under the assumption of convex or linear utility function with respect to the number of stars, his results indicate that one league will successfully employ all star players while the other leagues have no star available. Pepall and Rechards (2001) also examine two-sided competition in a duopoly market for differentiated products with one unique superstar and show the outcome of two-sided competition depends on downstream competition. In our paper, by contrast, players are homogeneous in their ability, but heterogeneous in their marginal valuation of the network externality. In addition, we consider two different channels for quality effects and show that the outcome of competition for inputs depends on the relative magnitude of product differentiation effect and wage reduction effect. This paper is concerned with the question how competitive balance effects embodied in consumers' utility affect the optimal choice of quality of teams and distribution of talented players via endogenous bidding functions.

The remainder of this paper is organized as follows. Section 2 sets up the basic two-period model from the two-sided market approach. For the players market, we introduce a distribution of player's marginal valuation of network effects and describe the player's team choice based on his utility. Then, we proceed to define the optimal bidding strategy for teams. For the consumer market, we construct a linear city model where team's quality is determined by the division of player talent held by each team. In this framework, we investigate how the two-sided externality affects the talent distribution 
among teams and the level of competition in the market for fans. In section 3 we extend the basic model by introducing team-specific relative quality on consumer's utility. After summarizing the policy implications and reproducing the invariance principle in section 4 , we offer some concluding remarks.

\section{Basic model}

\section{An Overview of the model}

We have three different types of agents participating in this two-sided market of professional team sports: consumers (fans), inputs (players), and platforms (teams). ${ }^{6} \mathrm{We}$ use Hotelling (1929)'s linear city model to describe consumers' behavior. There is a unit length of one where consumers, whose size is normalized to 1 , are uniformly distributed on the interval between 0 and 1 . At the beginning of the interval (i.e., at point 0 ), there is team A, and team B is located at the end of the interval (i.e., at point 1). Product A and B are horizontally differentiated and the value of products are dependent on the quality of each team. Let $\theta_{j}$ denote product $j$ 's quality which is determined by the portion of talented players team $j$ has. Each consumer has his favorite team in terms of his location in the interval but receives the same amount of valuation (i.e., $\theta_{j}$ ) from consuming product $j$. Let $x$ denote a consumer's location in the interval. Each consumer forms an expectation about each team's quality and consumes 0 or 1 unit, such as a season ticket, at the price of $p_{j}$ from team $j(j=A, B)$. Also, consumers are assumed to suffer disutility from choosing a variant that differs from their ideal. It is dependent upon their location $\left(x_{i}\right)$ in the interval, consumers incur disutility of $t x_{i}$ when they acquire the product $\mathrm{A}$ and $t\left(1-x_{i}\right)$ for product $\mathrm{B}$ where $t$ measures a degree of fans' loyalty towards teams. Teams set the price, $p$, of the ticket to maximize their revenues. Since the consumer's location, $x$, is private information, team $j$ cannot price discriminate and charges a uniform price of $p_{j}$.

\footnotetext{
${ }^{6}$ We may also think of this model as inter-league competition with two-sided network effects. In the case of the European football league, there are domestic leagues such as Premiership in England, Ligue 1 in France, Serie A in Italy, Liga in Spain, etc. Each domestic league should compete for both players and fans. Each domestic league's quality affects fan's willingness to pay for the game and, at the same time, a large number of fans increases a player's willingness to play for the league.
} 
Now we turn to the consumer's team choice where the valuation of product is high enough so that consumers buy at least product from ether of teams. For a given price and level of team quality, the net utility for a type- $x_{i}$ consumer is

$$
u\left(x_{i}\right)= \begin{cases}\left(\theta_{A}+\underline{\theta}\right)-p_{A}-t x_{i} & \text { if she buys a season ticket for team A } \\ \left(\theta_{B}+\underline{\theta}\right)-p_{B}-t\left(1-x_{i}\right) & \text { if she buys a season ticket for team B }\end{cases}
$$

Basically, the quality of each team is determined by the proportion of talented players on the team. There are two groups of players, the first group with high quality and the second with low quality. We assume that the second group of players has the minimal level of talent, so hiring them only affects the teams' quality up to the minimum quality level $\underline{\theta}$. Even if a team fails to hire any players from the first group, it is able to hire players from the second group at a wage of zero because there are a sufficient number of those players whose total contribution is limited as $\underline{\theta}$ regardless of the number of the mediocre players. The reservation wage of players in both groups is normalized to zero. Therefore, teams are only bidding for players from the first group because the team's quality depends on the number of players with positive quality in the team. For the rest of the paper, "players" refers only to talented ones. Talented players are assumed to be heterogeneous in their marginal valuations of the network externality from each team's fan size, but homogeneous in their contribution to team quality. For simplicity, we assume that the type of players $s$ (measuring the marginal valuation of network effects) is given by $s \sim U[0,1]$. Also, teams cannot observe individual valuation so that teams only offer a uniform wage of $w_{j}$.

Now we turn to a player's choice over different teams where his payoff from no activity is normalized to zero. Let us also assume a linear relationship between intergroup externality and the size of the fan base, $N_{j}=\beta q_{j}(j=A, B)$, where $\beta$ measures the intensity of network effects. We also assume that players' expectation should be fulfilled in equilibrium with perfect foresight, in which their expectations of fan base (i.e. $q_{j}^{e}$ ) actually equals the equilibrium fan base (i.e. $q_{j}^{*}$ ) in rational expectations equilibrium. 
Hereafter, we treat $q_{j}^{e}=q_{j}$. For a given set of $\left\{w_{A}, w_{B}, q_{A}, q_{B}\right\}$, the expected net utility for a type- $s_{k}$ player is given by

$$
u\left(s_{k}\right)= \begin{cases}\beta q_{A} s_{k}+w_{A} & \text { if she joins team A } \\ \beta q_{B} s_{k}+w_{B} & \text { if she joins team B }\end{cases}
$$

Teams set both the ticket price and wages in a two-stage game. In stage one, team $j$ sets the wage, $w_{j}$, which is the uniform wage offer for the proportion of players. In stage two, team $j$ sets the price, $p_{j}$, for its season tickets. Therefore, teams have to compete for both fans and players. To find the Subgame Perfect Nash equilibrium (SPNE), we begin with period two.

\section{Period two: competition for fans with given quality}

In period two, the two teams $(A$ and $B)$ with given quality levels of $\left(\theta_{A}, \theta_{B}\right)$ compete for fans. When consumers make their purchase decision, they choose the option that yields the highest net utility. When we consider the case of $\theta_{A}>\theta_{B}$, we have consumer $i$ 's utility for a given price and quality level as follows:

$$
\begin{array}{ll}
\left(\theta_{A}+\underline{\theta}\right)-p_{A}-t x_{i} & \text { purchase a season ticket for team A } \\
\left(\theta_{B}+\underline{\theta}\right)-p_{B}-t\left(1-x_{i}\right) & \text { purchase a season ticket for team B }
\end{array}
$$

Thus, for a given price and quality level, there will be a marginal consumer, who is indifferent between buying a season ticket from team $A$ and $B$, denoted as $\hat{x}$ if $\left(\theta_{A}+\underline{\theta}\right)-p_{A}-t x_{i}=\left(\theta_{B}+\underline{\theta}\right)-p_{B}-t\left(1-x_{i}\right)$.

Therefore, each team's demand is

$$
q_{A}=\hat{x}=\frac{t-p_{A}+p_{B}+\theta_{A}-\theta_{B}}{2 t} \text { and } q_{B}=1-\hat{x}=\frac{t-p_{B}+p_{A}+\theta_{B}-\theta_{A}}{2 t}
$$

When the marginal cost of serving consumers is assumed to be zero, team $j$ maximizes

$$
\underset{P_{j}}{\operatorname{Max}_{j}} p_{j} q_{j} \text { with } j=\{A, B\}
$$

After solving each team's revenue maximization problem, we have the equilibrium ticket price and sales as following: 


$$
p_{j}\left(\theta_{j}, \theta_{-j}\right)=t+\frac{\left(\theta_{j}-\theta_{-j}\right)}{3}, q_{j}\left(\theta_{j}, \theta_{-j}\right)=\frac{1}{2}+\frac{\theta_{j}-\theta_{-j}}{6 t}
$$

The corresponding equilibrium revenues are as follows:

$$
R_{j}\left(\theta_{j}, \theta_{-j}\right)=\frac{\left(3 t+\theta_{j}-\theta_{-j}\right)^{2}}{18 t}
$$

\section{Period one: competition for talented players}

Now we turn to period one in which teams make bids to hire players. When the player makes his decision over different teams, he chooses the one that yields the highest expected net utility given wage offers and the size of fan base. To find out which choice gives the highest net utility, without loss of generality, we assume that $N_{A}>N_{B}$, which team A has larger fan base compared to that of team B. From the quantity functions we derived in period two, each team's network externality is expressed as follows:

$$
N_{j}=\beta q_{j}\left(\theta_{j}, \theta_{-j}\right)=\beta\left(\frac{1}{2}+\frac{\theta_{j}-\theta_{-j}}{6 t}\right)
$$

In this setup, a player's optimal choice for a given wage and the size of fans can be divided as follows:

$$
\begin{array}{ll}
0 \leq s<\frac{w_{B}-w_{A}}{N_{A}-N_{B}} & \text { join team B } \\
\frac{w_{B}-w_{A}}{N_{A}-N_{B}} \leq s \leq 1 & \text { join team A }
\end{array}
$$

In this setup, we denote $\hat{s}$ as the critical type of player whose net utilities are indifferent between joining team $\mathrm{A}$ and $\mathrm{B}$ if $\beta q_{A} \hat{s}+w_{A}=\beta q_{B} \hat{s}+w_{B}$. As a result, the self-selection choice of players between teams is shown in Figure 1, which in turn determines the level of quality of teams in period one:

$$
\theta_{A}=1-\hat{s} \text { and } \theta_{B}=\hat{s} \text { when } N_{A}>N_{B} .
$$

Therefore, denoting $\hat{s}_{A}$ and $\hat{s}_{B}$, the best response of the portion of players of team A and respectively B given the other team's wage offer, each team's wage offer function is

$$
w_{A}\left(w_{B}\right)=w_{B}-\frac{\beta \hat{s}_{A}\left(1-2 \hat{s}_{A}\right)}{3 t}
$$




$$
w_{B}\left(w_{A}\right)=w_{A}+\frac{\beta \hat{s}_{B}\left(1-2 \hat{s}_{B}\right)}{3 t}
$$

These wage offer functions represent the relationship between the wage offer of team $j$ (i.e., $w_{j}$ ) and the team $j$ 's best response of the portion of talented players (i.e. $\hat{s}_{j}$ ) given the other team's wage offer (i.e. $w_{-j}$ ). It is very important to note that $\hat{s}_{j}$ is not the Nash equilibrium outcome, but the best strategy of team $j$ given $w_{-j}$, which is not consistent with $d \hat{s} / d \hat{s}_{j}=1$ or $d \hat{s}_{-j} / d \hat{s}_{j}=-1$ from 'fixed supply conjecture' in Quirk and Fork(1995). The Nash equilibrium outcome, $\hat{s}$ is determined in a non-cooperative bidding game by two teams; each team owner calculates his or her best response to given the other team's offer, which jointly determines the relative share of players and hence the quality of teams. After calculating independently the best response all possible wage offer of the other team, both team owners will propose $\left(w_{j}^{*}, w_{-j}^{*}\right)$, which yields $\hat{s}_{j}=\hat{s}_{-j}=\hat{s}$ at the equilibrium. It is the same logical procedure as a one-shot quantity-setting game with duopoly where each firm calculates the best response based on how his or her choice of quantity affects the market price and hence profits given expectation of the other firm's quantity. Applying the same logic, team A (B) chooses his or her best response based on how his choice will affect the quality of teams that is $d \theta_{A} / d \hat{s}_{A}=-1\left(d \theta_{B} / d \hat{s}_{B}=1\right)$.

To have more meaningful analysis of bidding functions of teams we impose the following constraints:

Non-negative bidding constraint: $w_{j} \geq 0$,

Non-negative profit constraint: $\pi_{j} \geq 0$,

where the non-negative bidding constraint eliminate cases in which the team with a larger fan base can not charge a negative price to players to join the team even though the network effect itself is bigger than the wage offer of the other team. Also, we rule out the case of myopic behavior of teams in which total spending for players exceeds revenue in period two.

With endogenous choice of quality at the first period, there exist two possible equilibrium configurations: (1) there is one team which hires all talented players; (2) both 
teams hire a positive portion of talented players. With the revenue function we found in period two, each team's profit function can be presented as follows:

$$
\begin{aligned}
& \pi_{A}\left(\hat{s}_{A}\right)=\frac{\left(3 t+1-2 \hat{s}_{A}\right)^{2}}{18 t}-w_{A}\left(1-\hat{s}_{A}\right) \\
& \pi_{B}\left(\hat{s}_{B}\right)=\frac{\left(3 t+2 \hat{s}_{B}-1\right)^{2}}{18 t}-w_{B} \hat{s}_{B}
\end{aligned}
$$

Let us first derive the best reaction function given $w_{B}$, in which team $\mathrm{A}$ maximizes $\pi_{A}\left(\hat{s}_{A}\right)$ with the constraint of equation (8a). Since the team A's wage offer $w_{A}$ is uniquely determined by $\hat{s}_{A}$ with given $w_{B}$, we will find it more convenient to treat $\hat{s}_{A}$ as the control variable. Differentiating $\pi_{A}\left(\hat{s}_{A}\right)$ of equation (9a) with respect to $\hat{s}_{A}$ gives us:

$$
\frac{\partial \pi_{A}\left(\hat{s}_{A}\right)}{\partial \hat{s}_{A}}=-\frac{1}{9 t}\left(2+6 t-3 \beta-2 \hat{s}_{A}\left(2-9 \beta+9 \beta \hat{s}_{A}\right)\right)+w_{B}
$$

which yields $\hat{s}_{A}^{*}>0$ when $\beta>2(1+3 t) / 3$. We denote $\hat{s}_{A}^{*}$ as the optimal level of players of team A satisfying equation (8a) and (10). Otherwise, we have the following best response function when $\beta \leq 2(1+3 t) / 3$ :

$$
w_{A}^{*}\left(w_{B}\right)= \begin{cases}w_{A}^{C^{*}}\left(w_{B}\right)=w_{B} \text { with } \hat{s}_{A}^{*}=0 & \text { if } w_{B} \leq \frac{2+6 t-3 \beta}{9 t} \\ w_{A}^{I^{*}}\left(w_{B}\right)=w_{B}-\frac{\beta \hat{s}_{A}^{*}\left(1-2 \hat{s}_{A}^{*}\right)}{3 t} \text { with } \hat{s}_{A}^{*}>0 & \text { if } w_{B}>\frac{2+6 t-3 \beta}{9 t}\end{cases}
$$

where $w_{A}^{C^{*}}(\cdot)$ and $w_{A}^{I^{*}}(\cdot)$ are the best-response functions of team A with the corner and interior solution respectively.

In similar fashion we calculate the best response function of team B. Team B's profit maximization problem is maximizing $\pi_{B}\left(\hat{s}_{B}\right)$ with the constraint of equation (8b). Differentiating $\pi_{B}\left(\hat{s}_{B}\right)$ of equation $(9 \mathrm{~b})$ with respect to $\hat{s}_{B}$ gives us:

$$
\frac{\partial \pi_{B}\left(\hat{s}_{B}\right)}{\partial \hat{s}_{B}}=\frac{1}{9 t}\left(-2+6 t+2 \hat{s}_{B}\left(2-3 \beta+9 \beta \hat{s}_{B}\right)\right)-w_{A}
$$


which yields $\hat{s}_{B}^{*}=0$ when $t \leq \frac{1}{3}$. We also denote $\hat{s}_{B}^{*}$ as the optimal level of players of team B satisfying equations ( $8 \mathrm{~b})$ and (12). Otherwise, we have the following bestresponse function of team $\mathrm{B}$ when $t>\frac{1}{3}$ :

$$
w_{B}^{*}\left(w_{A}\right)= \begin{cases}w_{B}^{C^{*}}\left(w_{A}\right)=w_{A} \text { with } \hat{s}_{B}^{*}=0 & \text { if } w_{A} \geq \frac{2(3 t-1)}{9 t} \\ w_{B}^{I^{*}}\left(w_{A}\right)=w_{A}+\frac{\beta \hat{s}_{B}^{*}\left(1-2 \hat{s}_{B}^{*}\right)}{3 t} \text { with } \hat{s}_{B}^{*}>0 & \text { if } w_{A}<\frac{2(3 t-1)}{9 t}\end{cases}
$$

where $w_{B}^{C^{*}}$ and $w_{B}^{I^{*}}$ are best-response functions of team B with the corner and interior solution respectively.

Proposition 1 The multiple Nash equilibria outcome to bidding for players with a positive level of talent are:

1) perfect imbalance outcome: If $t \geq \frac{1}{3}$ and $\beta \leq \frac{4}{3}$, we have $w_{A}=w_{B} \in\left[\frac{2(3 t-1)}{9 t}, \frac{2+6 t-3 \beta}{9 t}\right]$ and $\hat{s}^{*}=0$ which team A hires all high-quality players and team $\mathrm{B}$ hires none. The most profitable equilibrium for team $\mathrm{A}$ is $w_{A}=w_{B}=\frac{2(3 t-1)}{9 t}$;

2) alleviated imbalance outcome: If $t<\frac{1}{3}$ and $\beta>\frac{4}{3}$, we have

$$
\begin{aligned}
& w_{A}=\frac{16+6(-19+75 t-6 \beta) \beta}{675 \beta t}, w_{B}=\frac{-16+9(-14+50 t-\beta) \beta}{675 \beta t}, \text { and } \\
& \hat{s}^{*}=\frac{1}{5}-\frac{4}{15 \beta} \cdot{ }^{7}
\end{aligned}
$$

Proof. See the proof of proposition 3 in Appendix A since the outcomes in proposition 3 are identical to those in proposition 1 when $\Delta \gamma=0$ and $\alpha=1$.

\footnotetext{
${ }^{7}$ The non-negative bidding constraint needs to satisfy the following condition, $\beta<\frac{1}{12}\left(-19+75 t+5 \sqrt{17-114 t+225 t^{2}}\right)$.
} 
The intuition of proposition 1 is given. An increase in the relative share of players of the high-quality team induces two opposite effects: product differentiation effect and wage reduction effect due to externalities from the size of talented players and fans respectively. As the difference in qualities between teams increases it reduces price competition at period two due to the product differentiation effect, which makes the highquality team bid more aggressively to have more talented players. On the other hand, the wage reduction effects are also present. With an increase in the relative share of talented players, the high-quality team will have a larger fan base, which makes the high-quality team even more attractive to players. The high-quality team responds with a reduction wages of inframarginal players up to the point where player's utility is exactly compensated by the increased network externality from the fan size. As the intensity of the network effect increases, the high-quality team bids less aggressively for talented players since the wage reduction effect on inframarginal players becomes dominant. As a result, the alleviated competitive balance outcome prevails as equilibrium, and the highquality team actually gives up some of its players.

\section{Consumer's preference with competitive balance effects}

Up to this point, we have analyzed the effect of two-sided externalities in competition for player talent and fan base. In this section, we extend our model to analyze the markets of professional sports with consumer's preference with competitive balance effects. To analyze this issue, we explicitly introduce competitive balance effects in consumer's utility, which are assumed to be the difference between team qualities. Let us choose simple functional forms for the competitive balance effects such as

$$
\phi_{A}\left(\theta_{A}, \theta_{B}\right)=\gamma_{A}\left|\theta_{A}-\theta_{B}\right| \text { and } \phi_{B}\left(\theta_{A}, \theta_{B}\right)=\gamma_{B}\left|\theta_{A}-\theta_{B}\right| \text { for } 0 \leq \gamma_{j} \leq{\frac{\theta_{j}+\underline{\theta}}{\theta_{j}-\theta_{-j}}}^{8} \text {. }
$$

\footnotetext{
${ }^{8}$ The boundary of $\gamma_{j}$ is derived from the following condition: $0 \leq \theta_{j}+\underline{\theta}-\gamma_{j}\left(\theta_{j}-\theta_{-j}\right) \leq \theta_{j}+\underline{\theta}$ with an assumption of $\theta_{j} \geq \theta_{-j}$. The first inequality represents non-negative quality constraint of team $j$ and the second inequality defines the direction of competitive balance effects, which assumed to have negative impact on the quality of teams.
} 
Here, $\gamma_{j}$ captures the asymmetric nature of competitive balance effects on the quality of teams. For example, $\gamma_{j}$ being less than $\gamma_{-j}$ means that team $j$ suffers less from competitive imbalance effects. Thus, the utility of a fan is given by

$$
u\left(x_{i}\right)= \begin{cases}\left(\theta_{A}+\underline{\theta}-\gamma_{A}\left|\theta_{A}-\theta_{B}\right|\right)-p_{A}-t x_{i} & \text { if she buys a season ticket for team A } \\ \left(\theta_{B}+\underline{\theta}-\gamma_{B}\left|\theta_{A}-\theta_{B}\right|\right)-p_{B}-t\left(1-x_{i}\right) & \text { if she buys a season ticket for team } B\end{cases}
$$

In period two, the two teams $\{A, B\}$ compete for fans with given quality levels of $\left(\theta_{A}, \theta_{B}\right)$. When consumers make their purchase decision, they choose the option that yields the highest net utility. Assuming $\theta_{A}>\theta_{B}$ without loss of generality, we denote $\hat{x}^{C B}$ as a critical consumer whose utility embodied with competitive balance effects is the same from buying a ticket from either team if

$$
\left(\theta_{A}+\underline{\theta}-\gamma_{A}\left(\theta_{A}-\theta_{B}\right)\right)-p_{A}-t \hat{x}^{C B}=\left(\theta_{B}+\underline{\theta}-\gamma_{B}\left(\theta_{A}-\theta_{B}\right)\right)-p_{B}-t\left(1-\hat{x}^{C B}\right)^{9}
$$

Given the location of the critical consumer we calculate each team's demand as follows:

$$
\begin{aligned}
& q_{A}^{C B}=\hat{x}^{C B}=\frac{1}{2 t}\left(t-p_{A}^{C B}+p_{B}^{C B}+(1-\Delta \gamma)\left(\theta_{A}^{C B}-\theta_{B}^{C B}\right)\right) \\
& q_{B}^{C B}=1-\hat{x}^{C B}=\frac{1}{2 t}\left(t-p_{B}^{C B}+p_{A}^{C B}+(1-\Delta \gamma)\left(\theta_{B}^{C B}-\theta_{A}^{C B}\right)\right)
\end{aligned}
$$

where $\Delta \gamma=\gamma_{A}-\gamma_{B}$. With the competitive balance effects on consumer's preferences, there is no change in the revenue function for each team in period two. Therefore, we now derive the optimal price of each team's maximizing equation (4). After solving each team's revenue maximization problem, we have the equilibrium ticket price and sales as following:

$$
\begin{aligned}
& p_{j}^{C B}\left(\theta_{j}^{C B}, \theta_{-j}^{C B}\right)=t+\frac{(1-\Delta \gamma)\left(\theta_{j}^{C B}-\theta_{-j}^{C B}\right)}{3}, \\
& q_{j}^{C B}\left(\theta_{j}^{C B}, \theta_{-j}^{C B}\right)=\frac{1}{2}+\frac{(1-\Delta \gamma)\left(\theta_{j}^{C B}-\theta_{-j}^{C B}\right)}{6 t}
\end{aligned}
$$

The corresponding equilibrium revenues are:

$$
R_{j}^{C B}\left(\theta_{j}^{C B}, \theta_{-j}^{C B}\right)=\frac{\left(3 t+(1-\Delta \gamma)\left(\theta_{j}^{C B}-\theta_{-j}^{C B}\right)\right)^{2}}{18 t}
$$

\footnotetext{
${ }^{9}$ Superscript, CB, in variables denotes analysis in the case of competitive balance effects.
} 
where $\Delta \gamma=\gamma_{j}-\gamma_{-j}$. From the quantity functions we derived in period two, each team's network externality with competitive balance effects becomes:

$$
\begin{aligned}
& N_{A}^{C B}=\beta q_{A}^{C B}\left(\theta_{A}^{C B}, \theta_{B}^{C B}\right)=\beta\left(\frac{1}{2}+\frac{(1-\Delta \gamma)\left(\theta_{A}^{C B}-\theta_{B}^{C B}\right)}{6 t}\right) \\
& N_{B}^{C B}=\beta q_{B}^{C B}\left(\theta_{A}^{C B}, \theta_{B}^{C B}\right)=\beta\left(\frac{1}{2}+\frac{(1-\Delta \gamma)\left(\theta_{B}^{C B}-\theta_{A}^{C B}\right)}{6 t}\right)
\end{aligned}
$$

Since the optimal choice of players only depends on the size of the fan base and the wage offer from teams we reiterate the notion of finding the critical type of player such as $\hat{s}^{C B}$ if $\beta q_{A}^{C B} \hat{S}^{C B}+w_{A}^{C B}=\beta q_{B}^{C B} \hat{S}^{C B}+w_{B}^{C B}$. As a result, the level of quality for teams in period one is uniquely determined by $\hat{s}^{C B}$ :

$$
\theta_{A}^{C B}=1-\hat{s}^{C B} \text { and } \theta_{B}^{C B}=\hat{s}^{C B} \text { when } q_{A}^{C B}>q_{B}^{C B} .
$$

Therefore, each team's wage offer function, equations $(8 a)$ and $(8 b)$ in the basic model becomes

$$
\begin{aligned}
& w_{A}^{C B}\left(w_{B}^{C B}\right)=w_{B}^{C B}-\frac{\beta(1-\Delta \gamma) \hat{s}_{A}^{C B}\left(1-2 \hat{s}_{A}^{C B}\right)}{3 t} \\
& w_{B}^{C B}\left(w_{A}^{C B}\right)=w_{A}^{C B}+\frac{\beta(1-\Delta \gamma) \hat{s}_{B}^{C B}\left(1-2 \hat{s}_{B}^{C B}\right)}{3 t}
\end{aligned}
$$

With the revenue function we found in period two, each team's profit function can be presented as follows:

$$
\begin{aligned}
& \pi_{A}^{C B}\left(\hat{s}_{A}^{C B}\right)=\frac{\left(3 t+1-\Delta \gamma-2(1-\Delta \gamma) \hat{s}_{A}^{C B}\right)^{2}}{18 t}-w_{A}^{C B}\left(1-\hat{s}_{A}^{C B}\right) \\
& \pi_{B}^{C B}\left(\hat{s}_{B}^{C B}\right)=\frac{\left(3 t-1+\Delta \gamma+2(1-\Delta \gamma) \hat{s}_{B}^{C B}\right)^{2}}{18 t}-w_{B}^{C B} \hat{s}_{B}^{C B}
\end{aligned}
$$

Let us first derive the best reaction function given $w_{B}^{C B}$, in which team A maximizes $\pi_{A}^{C B}\left(\hat{s}_{A}^{C B}\right)$ with the constraint of equation (19a). Differentiating $\pi_{A}^{C B}$ of equation (20a) with respect to $\hat{s}_{A}^{C B}$ gives us: 
$\frac{\partial \pi_{A}^{C B}}{\partial \hat{s}_{A}^{C B}}=-\frac{1}{9 t}(1-\Delta \gamma)\left(2+6 t-3 \beta-2 \Delta \gamma+2(-2+9 \beta+2 \Delta \gamma) \hat{s}_{A}^{C B}-18 \beta\left(\hat{s}_{A}^{C B}\right)^{2}\right)+w_{B}$

which yields $\hat{s}_{A}^{C B^{*}}>0$ when $\beta>\frac{2}{3}(3 t+1-\Delta \gamma)$. We denote $\hat{s}_{A}^{C B^{*}}$ as the optimal level of players of team A satisfying equations (19a) and (21). Otherwise, we have the following best response function when $\beta \leq \frac{2}{3}(3 t+1-\Delta \gamma)$ :

$$
w_{A}^{C B^{*}}\left(w_{B}^{C B}\right)=\left\{\begin{aligned}
w_{A}^{C^{*}}\left(w_{B}^{C B}\right)=w_{B}^{C B} \text { with } \hat{s}_{A}^{C B^{*}}=0 \quad \text { if } w_{B}^{C B} \leq \frac{(1-\Delta \gamma)(2+6 t-3 \beta-2 \Delta \gamma)}{9 t} \\
w_{A}^{I^{*}}\left(w_{B}^{C B}\right)=w_{B}^{C B}-\frac{\beta(1-\Delta \gamma) \hat{s}_{A}^{C B^{*}}\left(1-2 \hat{s}_{A}^{C B^{*}}\right)}{3 t} \text { with } \hat{s}_{A}^{C B^{*}}>0 \\
\quad \text { if } w_{B}^{C B}>\frac{(1-\Delta \gamma)(2+6 t-3 \beta-2 \Delta \gamma)}{9 t}
\end{aligned}\right.
$$

In similar fashion we calculate the best response function of team B. Team B's profit maximization problem is maximizing $\pi_{B}\left(\hat{S}_{B}\right)$ with the constraint of equation (19b). Differentiating $\pi_{B}^{C B}$ of equation (20b) with respect to $\hat{s}_{B}$ gives us:

$$
\frac{\partial \pi_{B}^{C B}}{\partial \hat{s}_{B}^{C B}}=-\frac{2}{9 t}(1-\Delta \gamma)\left(1-3 t-\Delta \gamma+(-2+3 \beta+2 \Delta \gamma) \hat{s}_{B}^{C B}-9 \beta\left(\hat{s}_{B}^{C B}\right)^{2}\right)-w_{A}
$$

which yields $\hat{S}_{B}^{C B^{*}}=0$ when $t \leq \frac{1-\Delta \gamma}{3}$. We also denote $\hat{s}_{B}^{*}$ as the optimal level of players of team B satisfying equation (19b) and (23). Otherwise, we have the following best-response function of team B when $t>\frac{1-\Delta \gamma}{3}$ :

$$
w_{B}^{C B^{*}}\left(w_{A}^{C B}\right)=\left\{\begin{array}{r}
w_{B}^{C *}\left(w_{A}^{C B}\right)=w_{A}^{C B} \text { with } \hat{s}_{B}^{C B^{*}}=0 \quad \text { if } w_{A}^{C B} \geq \frac{(1-\Delta \gamma)(6 t-2+2 \Delta \gamma)}{9 t} \\
w_{B}^{I^{*}}\left(w_{A}^{C B}\right)=w_{A}^{C B}+\frac{\beta \hat{s}_{B}^{C B^{*}}(1-\Delta \gamma)\left(1-2 \hat{s}_{B}^{C B^{*}}\right)}{3 t \quad \text { with } \hat{s}_{B}^{C B^{*}}>0} \\
\text { if } w_{A}^{C B}<\frac{(1-\Delta \gamma)(6 t-2+2 \Delta \gamma)}{9 t}
\end{array}\right.
$$


Proposition 2 The multiple Nash equilibria outcomes to bidding for players with a positive level of talent when we explicitly introduce competitive balance effects on consumer's utility are

1) perfect imbalance outcome: If $t \geq \frac{1-\Delta \gamma}{3}$ and $\beta \leq \frac{4}{3}(1-\Delta \gamma)$, we have

$$
w_{A}^{C B}=w_{B}^{C B} \in\left[\frac{(1-\Delta \gamma) 2(3 t-1+\Delta \gamma)}{9 t}, \frac{(1-\Delta \gamma)(2+6 t-3 \beta-2 \Delta \gamma)}{9 t}\right] \text { and } \hat{s}^{C B^{*}}=0
$$

where team A hires all high-quality players and team B hires none. The best equilibrium for team $\mathrm{A}$ is $w_{A}^{C B^{*}}=w_{B}^{C B^{*}}=\frac{(1-\Delta \gamma) 2(3 t-1+\Delta \gamma)}{9 t}$;

2) alleviated imbalance outcome:

If $t<\frac{1-\Delta \gamma}{3}$ and $\beta>\frac{4}{3}(1-\Delta \gamma)$, we have

$$
\begin{aligned}
& w_{A}^{C B^{*}}=\frac{2(1-\Delta \gamma)\left(-18 \beta^{2}+3 \beta\left(75 t-19(1-\Delta \gamma)+8(1-\Delta \gamma)^{2}\right)\right)}{675 \beta t}, \\
& w_{B}^{C B^{*}}=\frac{-(1-\Delta \gamma)\left(9 \beta^{2}+16(1-\Delta \gamma)^{2}-18 \beta(-7+25 t+7 \Delta \gamma)\right)}{675 \beta t}, \text { and } \\
& \hat{S}^{C B^{*}}=\frac{1}{5}-\frac{4(1-\Delta \gamma)}{15 \beta} \cdot{ }^{10}
\end{aligned}
$$

Proof. See the proof of proposition 3 in Appendix A since the outcomes in proposition 3 are identical to those in proposition 2 when $\alpha=1$.

Intuition of proposition 2 is simple. The threshold of $\beta$ between perfectly and alleviated competitive imbalance equilibrium and the optimal share of talented player are dependent upon the sign and scale of $\Delta \gamma$. For example, when $\Delta \gamma$ is positive and increasing, fans of the high-quality team become more concerned about the relative quality, the high-quality team has less incentive to pursue talented players aggressively. In other words, the product differentiation effect becomes small whereas the wage reduction effect remains

10 The non-negative bidding constraint needs to satisfy the following condtion, $\beta<\frac{1}{12}\left(-19+75 t-19 \Delta \gamma+5 \sqrt{17(1-\Delta \gamma)^{2}-114 t(1-\Delta \gamma)+225 t^{2}}\right)$. 
the same so that we observe lower threshold of $\beta$ in the perfect imbalance equilibrium and higher value of $\hat{s}^{C B}$ in the alleviated one.

\section{Policy Implication}

\section{Revenue Sharing}

Now we introduce a simple model of quality choice of each team with revenue sharing. Traditional revenue sharing refers to the case where the home club gives the visiting club a share of gate revenue for each game play. To implement the traditional revenue sharing system in the two-sided markets, we denote $\alpha \in\left[\frac{1}{2}, 1\right]$ as the revenue sharing parameter, which is the share of team $j$ 's revenue that stays and $(1-\alpha)$ share of its revenue goes to team $-j$. In this simple revenue sharing scheme, teams are assumed to be prevented from cooperating in neither pricing nor bidding for the players. It means that teams still compete against each other in two periods in terms of pricing for season ticket and bidding for the players but they should take into account the effect of revenue sharing on their decisions. Since there is no change in the nature of competition in both periods, we write the profit functions under the revenue sharing scheme with competitive balance effects as

$$
\begin{aligned}
& \pi_{A}^{R S}=\alpha R_{A}^{R S}+(1-\alpha) R_{B}^{R S}-w_{A}\left(1-\hat{s}_{A}^{R S}\right) \\
& \pi_{B}^{R S}=\alpha R_{B}^{R S}+(1-\alpha) R_{A}^{R S}-w_{B} \hat{S}_{B}^{R S}
\end{aligned}
$$

where $R_{j}^{R S}$ and each team's wage offer functions are the same as equations (17), (19a) and (19b) respectively. Differentiating the profit functions for team A and B yields

$$
\frac{\partial \pi_{A}^{R S}}{\partial \hat{s}_{A}^{R S}}=-\frac{1}{9 t}(1-\Delta \gamma)\left(2+6 t(2 \alpha-1)-3 \beta-2 \Delta \gamma+2(-2+9 \beta+2 \Delta \gamma) \hat{s}_{A}^{C B}-18 \beta\left(\hat{s}_{A}^{C B}\right)^{2}\right)+w_{B}
$$

(26a),

$$
\frac{\partial \pi_{B}^{R S}}{\partial \hat{s}_{B}^{R S}}=-\frac{2}{9 t}(1-\Delta \gamma)\left(1+3 t(1-2 \alpha)-\Delta \gamma+(-2+3 \beta+2 \Delta \gamma) \hat{s}_{B}^{C B}-9 \beta\left(\hat{s}_{B}^{C B}\right)^{2}\right)-w_{A}
$$


We again denote $\hat{s}_{A}^{R S^{*}}$ as the optimal level of players of team A satisfying equation (19a) and (26a). When $\beta>2(2 \alpha-1) t+\frac{2(1-\Delta \gamma)}{3}$, equation (26a) is always positive for any $w_{B}^{R S} \in[0, \infty]$, which yields $\hat{s}_{A}^{R S *}>0$. Otherwise, we have the following best response function when $\beta \leq 2(2 \alpha-1) t+\frac{2(1-\Delta \gamma)}{3}$ :

$$
w_{A}^{R S^{*}}\left(w_{B}^{R S}\right)=\left\{\begin{array}{c}
w_{A}^{C^{*}}\left(w_{B}^{R S}\right)=w_{B}^{R S} \text { with } \hat{s}_{A}^{R S^{*}}=0 \\
\quad \text { if } w_{B}^{R S} \leq \frac{(1-\Delta \gamma)(2+6 t(2 \alpha-1)-3 \beta-2 \Delta \gamma)}{9 t} \\
w_{A}^{I^{*}}\left(w_{B}^{R S}\right)=w_{B}^{R S}-\frac{\beta(1-\Delta \gamma) \hat{s}_{A}^{R S^{*}}\left(1-2 \hat{s}_{A}^{R S^{*}}\right)}{3 t} \text { with } \hat{s}_{A}^{R S^{*}}>0 \\
\text { if } w_{B}^{R S}>\frac{(1-\Delta \gamma)(2+6 t(2 \alpha-1)-3 \beta-2 \Delta \gamma)}{9 t}
\end{array}\right.
$$

In similar fashion we calculate the best response function of team B. Denoting $\hat{s}_{B}^{R S^{*}}$ as the optimal level of players of team B satisfying equations (19b) and (26b) we have $\hat{S}_{B}^{R S^{*}}=0$ for any $w_{A}^{R S} \in[0, \infty]$ when $t \leq \frac{1-\Delta \gamma}{3(2 \alpha-1)}$. Otherwise, we have the following best-response function of team B when $t>\frac{1-\Delta \gamma}{3(2 \alpha-1)}$ :

$$
w_{B}^{R S^{*}}\left(w_{A}^{R S}\right)=\left\{\begin{aligned}
w_{B}^{C^{*}}\left(w_{A}^{R S}\right)=w_{A}^{R S} \text { with } \hat{s}_{B}^{R S^{*}}=0 & \\
& \text { if } w_{A}^{R S} \geq \frac{(1-\Delta \gamma)(6 t(2 \alpha-1)-2+2 \Delta \gamma)}{9 t} \\
w_{B}^{I^{*}}\left(w_{A}^{R S}\right)=w_{A}^{R S}+\frac{\beta \hat{s}_{B}^{R S^{*}}(1-\Delta \gamma)\left(1-2 \hat{s}_{B}^{R S^{*}}\right)}{3 t} \text { with } \hat{s}_{B}^{R S^{*}}>0 & \\
& \text { if } w_{A}^{R S}<\frac{(1-\Delta \gamma)(6 t(2 \alpha-1)-2+2 \Delta \gamma)}{9 t}
\end{aligned}\right.
$$

Proposition 3 The multiple Nash equilibria outcomes to bidding for players with a positive level of talent when we explicitly introduce competitive balance effects on consumer's utility under the revenue sharing scheme are 
1) perfect imbalance outcome: If $t \geq \frac{1-\Delta \gamma}{3(2 \alpha-1)}$ and $\beta \leq \frac{4}{3}(1-\Delta \gamma)$, we have

$w_{A}^{R S^{*}}=w_{B}^{R S^{*}} \in\left[\frac{(1-\Delta \gamma) 2(3 t(2 \alpha-1)-1+\Delta \gamma)}{9 t}, \frac{(1-\Delta \gamma)(2+6 t(2 \alpha-1)-3 \beta-2 \Delta \gamma)}{9 t}\right]$ and $\hat{s}^{R S^{*}}=0$ where team A hires all high-quality players and team $\mathrm{B}$ hires none.

The best equilibrium for team $\mathrm{A}$ is $w_{A}^{R S^{*}}=w_{B}^{R S^{*}}=\frac{(1-\Delta \gamma) 2(3 t(2 \alpha-1)-1+\Delta \gamma)}{9 t}$;

2) alleviated imbalance outcome:

$$
\begin{aligned}
& \text { If } t<\frac{1-\Delta \gamma}{3(2 \alpha-1)} \text { and } \beta>\frac{4}{3}(1-\Delta \gamma) \text {, we have } \\
& w_{A}^{R S^{*}}=\frac{2(1-\Delta \gamma)\left(-18 \beta^{2}+3 \beta\left(75 t(2 \alpha-1)-19(1-\Delta \gamma)+8(1-\Delta \gamma)^{2}\right)\right)}{675 \beta t}, \\
& w_{B}^{R S^{*}}=\frac{-(1-\Delta \gamma)\left(9 \beta^{2}+16(1-\Delta \gamma)^{2}-18 \beta(-7+25 t(2 \alpha-1)+7 \Delta \gamma)\right)}{675 \beta t}, \text { and } \\
& \hat{S}^{R S^{*}}=\frac{1}{5}-\frac{4(1-\Delta \gamma)}{15 \beta} .{ }^{11}
\end{aligned}
$$

Proof. See Appendix A

\section{Comparison}

We now compare the optimal division of the talented players, each team's wage offer, and ticket price under scenarios with and without competitive balance effects to the one with the revenue sharing scheme.

A simple comparison of expressions for $\hat{s}^{*}, \hat{s}^{C B^{*}}$ and $\hat{s}^{R S^{*}}$ in cases of alleviated imbalanced outcome under different regimes provides that the optimal division of players with competitive balance effects (i.e., $\hat{s}^{C B^{*}}$ ) and the one with the revenue sharing scheme (i.e., $\hat{s}^{R S^{*}}$ ) are the same, which suggests that revenue sharing has no impact on competitive balance. Intuitively, when revenues are shared, the team's bidding for

\footnotetext{
${ }^{11}$ The non-negative bidding constraint needs to satisfy the following condition, $\beta<\frac{1}{12}\left(-19+75 t(2 \alpha-1)-19 \Delta \gamma+\frac{1}{3} \sqrt{(225 t(2 \alpha-1)+57(1-\Delta \gamma))^{2}+576(1-\Delta \gamma)^{2}}\right)$.
} 
players should take into account the impact of their bidding on revenue of both teams. Due to the 'maximal product differentiation principle', the negative marginal impact on the high-quality team's revenue of increase in share of talents by the low-quality team is greater than the negative marginal impact on the low-quality team's revenue of decrease in the share of talents by the high-quality team, which means neither of teams have any incentive to reduce the quality gap with the revenue sharing scheme. At the same time, in the case of alleviated equilibrium the high-quality team gives up some talents due to the presence of wage reduction effect, which means the high-quality team never wants to hire more talented players. From these intuitions, revenue sharing has no impact on competitive balance. On the other hand, the competitive balance effects on the division of players depend on the asymmetric nature of the effects between teams. In detail, we have $\hat{s}^{*}-\hat{s}^{C B^{*}}=-4 \Delta \gamma=-4\left(\gamma_{A}-\gamma_{B}\right)$, which yields $\hat{s}^{*}>\hat{s}^{C B^{*}}$ if $\gamma_{A}<\gamma_{B}$. Otherwise, we have $\hat{s}^{*}<\hat{S}^{C B^{*}}$.

Given the fact that revenue sharing has no impact on competitive balance, we now compare wage offer of teams under the extended model to the one with revenue sharing scheme, in which a simple computation yields $w_{j}^{C B^{*}}-w_{j}^{R S^{*}}=\frac{4}{3}(1-\alpha)(1-\Delta \gamma)>0$. The more revenues are shared as $\alpha$ decreases, the less wages are offered to players due to the reduced incentive for teams to compete for the talented players. On the other hand, the direct comparison between wage offer of each team with competitive balance effect and the one without the effects is inconclusive. However, we are able to calculate the difference between total wages under two regimes:

$$
\left(w_{A}^{C B^{*}}+w_{B}^{C B^{*}}\right)-\left(w_{A}^{*}+w_{B}^{*}\right)=-\frac{1}{45 t} \Delta \gamma\left(\Delta \gamma-\frac{32-60 t+3 \beta}{16}\right)
$$

which has two roots at $\Delta \gamma=0$ and $\Delta \gamma=(32-60 t+3 \beta) / 16$. The condition in which the total wages with competitive balance effect exceeds the one without is given by

$$
\sum w_{j}^{C B^{*}}-\sum w_{j}^{*}=\left(w_{A}^{C B^{*}}+w_{B}^{C B^{*}}\right)-\left(w_{A}^{*}+w_{B}^{*}\right)>0\left\{\begin{array}{l}
\text { with } \Delta \gamma \in\left[0, \frac{32-60 t+3 \beta}{16}\right] \text { if } \beta>20 t-\frac{32}{3} \\
\text { with } \Delta \gamma \in\left[\frac{32-60 t+3 \beta}{16}, 0\right] \text { if } \beta<20 t-\frac{32}{3}
\end{array} .\right.
$$


In the case of the perfect imbalanced outcome under different regimes we have for $\hat{s}^{*}=\hat{s}^{C B^{*}}=\hat{s}^{R S^{*}}=0$, but it is noteworthy to illustrate how regions of no solution (colored with white, NC hereafter), alleviated imbalanced outcome (colored with light grey, AI hereafter) and imbalanced outcome (colored with dark grey, I hereafter) are affected by introducing different effects. Figures 6 and 7 measure the exogenous parameters $t$ on the horizontal axis and $\beta$ on the vertical axis. In figure 6 we illustrate the impact of introducing the competitive balance effect on consumers' utility function, in which black and blues lines represent various binding constraints dividing NC, AI, and I regions in the basic and extended model respectively. The AI and I regions shrink with competitive balance effects. The non-negative bidding and profit constraints binding AI region and I region, respectively, shift to the right in which there are fewer values of $t$ and $\beta$ for which the alleviated imbalanced outcome occurs. However, reading the graph from bottom to top the network intensity increases in which both teams start to have talented players at a threshold of $\beta=4 / 3$ in the basic model. In the extended model with the case of $\gamma_{A}>\gamma_{B}$, the threshold is reduced to $\beta=4(1-\Delta \gamma) / 3$, which implies team $\mathrm{A}$ is more likely to give up some talented players at the lower threshold due to the biased competitive balance effects.

Introducing the revenue sharing scheme has similar effects as the competitive balance effects. Again, we use the black and blue lines to illustrate the binding constraints in the extended model with competitive balance effects and the one with revenue sharing scheme respectively in figure 7 . Revenue sharing scheme tend to reduce the set of parameter values such as there is alleviated imbalanced outcome. However, there is no change in non-negative profit constraints which is the same at $\beta=(1-\Delta \gamma) / 3$ and the threshold for sharing talented players also remained unchanged at $\beta=4(1-\Delta \gamma) / 3$, which indicates again no impact of revenue sharing on enhancing competitive balance.

In terms of ticket price, we easily anticipate that there is no change in price in the extended model nor the one with revenue sharing effects since the nature of competition in period two remains the same. On the other hand, the team-specific competitive balance effects provide the team with larger $\gamma$ less incentive to hire talented players and 
thus it has less talented players compared to that in the basic model. As a result, it will end up offering a lower ticket price. The following proposition 4 and Table 1 summarize the above comparisons.

Proposition 4. Competitive balance effects on the optimal division of talented players and wage offer critically depend on the asymmetric nature of the effects. At the same time, the fixed-ratio revenue sharing scheme has no effect on competitive balance between teams, but reduces the optimal wage offer for the talented players.

Proof. See Appendix B.

\begin{tabular}{|c|c|c|c|}
\hline \multicolumn{2}{|r|}{ variables } & $\gamma_{A}>\gamma_{B}$ & $\gamma_{A}<\gamma_{B}$ \\
\hline & $\hat{s}$ & $\hat{s}^{*}<\hat{S}^{C B^{*}}=\hat{S}^{R S^{*}}$ & $\hat{S}^{*}>\hat{S}^{C B^{*}}=\hat{S}^{R S^{*}}$ \\
\hline \multirow[t]{2}{*}{$w^{*}$} & $\begin{array}{c}\text { Alleviated } \\
\text { imbalanced } \\
\text { equilibrium }\end{array}$ & $\begin{array}{c}w_{j}^{C B^{*}}>w_{j}^{R S^{*}} \\
\sum w_{j}^{C B^{*}}>\sum w_{j}^{*} \text { if } \beta>20 t-32 / 3 \\
\sum w_{j}^{C B^{*}}<\sum w_{j}^{*} \text { if } \beta<20 t-32 / 3\end{array}$ & $\begin{array}{c}w_{j}^{C B^{*}}>w_{j}^{R S^{*}} \\
\sum w_{j}^{C B^{*}}<\sum w_{j}^{*} \text { if } \beta>20 t-32 / 3 \\
\sum w_{j}^{C B^{*}}>\sum w_{j}^{*} \text { if } \beta<20 t-32 / 3\end{array}$ \\
\hline & $\begin{array}{l}\text { Imbalanced } \\
\text { equilibrium }\end{array}$ & $\begin{array}{c}w_{j}^{C B^{*}}>w_{j}^{R S^{*}} \\
E\left(w^{*}\right)>E\left(w^{C B^{*}}\right)\end{array}$ & $\begin{array}{c}w_{j}^{C B^{*}}>w_{j}^{R S^{*}} \\
E\left(w^{*}\right)<E\left(w^{C B^{*}}\right)\end{array}$ \\
\hline \multirow[t]{2}{*}{$p^{*}$} & $\begin{array}{c}\text { Alleviated } \\
\text { imbalanced } \\
\text { equilibrium }\end{array}$ & $\begin{array}{c}p^{C B^{*}}=p^{R S^{*}} \\
p_{A}^{C B^{*}}<p_{A}^{*} \text { and } p_{B}^{C B^{*}}>p_{B}^{*}\end{array}$ & $\begin{array}{c}p^{C B^{*}}=p^{R S^{*}} \\
p_{A}^{C B^{*}}>p_{A}^{*} \text { and } p_{B}^{C B^{*}}<p_{B}^{*}\end{array}$ \\
\hline & $\begin{array}{l}\text { Imbalanced } \\
\text { equilibrium }\end{array}$ & $\begin{array}{c}p^{C B^{*}}=p^{R S^{*}} \\
p_{A}^{C B^{*}}<p_{A}^{*} \text { and } p_{B}^{C B^{*}}>p_{B}^{*}\end{array}$ & $\begin{array}{c}p^{C B^{*}}=p^{R S^{*}} \\
p_{A}^{C B^{*}}>p_{A}^{*} \text { and } p_{B}^{C B^{*}}<p_{B}^{*}\end{array}$ \\
\hline
\end{tabular}

Table 1. Comparisons of the optimal values under different regimes

\section{Concluding Remarks}

In this paper, we analyze issues associated with network effects and twosidedness in the market for professional sports. Unlike previous work on two-sided 
markets we introduce players' quality as a medium to affect fan's demand so that the level of competition in the market for fans critically depends on the distribution of the number of high quality players between teams. Teams in professional sports leagues have to compete both for players (inputs) and fans (consumers). In this setting, two-sided network effects are important since fans are more attracted to a team with a larger portion of talented players from a fixed pool and, at the same time, players want to play for a team in the big market.

This paper provides new, important insights to the literature on competitive balance. Most of the past studies on competitive balance examine asymmetric teams with contest models (e.g., El-Hodiri and Quirk 1971; Fort and Quirk 1995; Vrooman 1995; Késenne 2000; Késenne and Szymanski 2004). Compared to the previous studies, this paper has some unique features. First of all, we incorporate heterogeneous valuation of the network externality into the players' labor supply function in order to show the impact of the network externality on talent distribution between teams and competition in the consumer market. The main contribution of this paper on the literature is that even with symmetric nature of teams we observe perfect or alleviated imbalance equilibrium due to the two-sided network externalities. Secondly, to analyze the importance of competitive balance issue in professional sports leagues we incorporate asymmetric teams-quality gap effects into consumers' utility. We show that the inclusion of quality gap creates more or less a balanced distribution of talented players between teams than the benchmark analysis depending on the nature of team-specific competitive balance effects and may enhance competition in the consumer market. We also claim to be the first to adopt an endogenous wage offer function of teams for players and to analyze the effect of revenue sharing on competitive balance and the level of wage offer for the talented players. In this setting, we derive the invariance principle without assuming fixed supply conjectural variation (Quirk and Fork, 1995). Our results rather are driven product differentiation and wage reduction effects by two-sided network externalities.

This paper provides a possible policy recommendation for improving competitive balance of a professional team league. If competitive imbalance occurs due to two-sided network externalities even with symmetric teams in all other aspects, one possible remedy for reducing competitive imbalance is to reduce the market share of the high- 
quality team which provides 'a level playing field' for the low quality team to attract talented players by locationing more teams near the high-quality team. Within this linear city model, it can be interpreted as the low quality team moving towards the center of the city in order to increase the market share. 


\section{References}

Anderson, S. and Coate, S., "Market Provision of Broadcasting: A Welfare Analysis," 2003, mimeo Cornell University.

Armstrong, M., "Competition in Two-Sided Markets," presentation at ESEM meeting, Venice, August 2002.

Baye, M., and J. Morgan, J., "Information Gatekeepers on the Internet and the Competitiveness of Homogeneous Product Markets," American Economic Review, 2001, $91,454-474$.

Burger, J. and Walters, S., "Market Size, Pay and Performance: A General Model and Application to Major League Baseball," Journal of Sports Economics, 2003, 108-125.

Caillaud, B., and B. Jullien, B., "Chicken and Egg: Competition Among Intermediation Service Providers," Rand Journal of Economics, 2003, 34(2), 309-328.

Cave, M., and Crandall, W., "Sports rights and the broadcast industry", Economic Journal, 2001, 111, 4-26.

El Hodiri, M., and Quirk, J., “An Economic Model of a Professional Sports League”, Journal of Political Economy, 1971, 79, 1302-19.

Evans, D. S., "The Antitrust Economics of Multi-Sided Platform Markets," Yale Journal on Regulation, 2003, 20(2), 325-82.

Frascatore, M. R., "The Grouping of Stars: An Application to Professional Sports," International Journal of Industrial Organization, 1999, 17, 1009-1027.

Fort, R., and Quirk, J., "Cross subsidization, Incentives and Outcomes in Professional Team Sports Leagues,” Journal of Economic Literature, 1995, 33, 1265-1299.

Fort, R., "Talent Market Models in North American and World Leagues." In Placido Rodriguez, Stefan Kesenne, and Jaume Garcia (eds.) Sports Economics after Fifty Years: Essays in Honour of Simon Rottenberg (Oviedo, Spain: Oviedo University Press), 2006, 83-106.

Hotelling, H., "Stability in Competition," Economic Journal, 1929, 39, 41-57.

Késenne, S., "Revenue Sharing and Competitive Balance in Professional Team Sports," Journal of Sports Economics, 2000, 11, 56-65.

Pepall, L. M., and Richards, D. I., "Reach for the Stars: A Strategic Bidding Game," Economica, 2001, 68, 489-503.

Rochet, J. C., and J. Tirole, J., "Platform Competition in Two- Sided Markets," Journal of 
the European Economic Association, 2003, 1(4), 990-1029.

Rochet, J. C., and Tirole, J., "Defining Two-Sided Markets," 2004, mimeo, University of Toulouse.

Rottenberg, S., “The Baseball Players' Labor Market," Journal of Polictical Economy, 1956, 64, 242-258.

Rysman, M., "Competition Between Networks: A Study of the Market for Yellow Pages," Review of Economic Studies, 2003, forthcoming.

Schmalensee, R., "Payment Systems and Interchange Fees," Journal of Industrial Economics, 2002, 50, 103-122.

Szymanski, S., "Professional Team Sports Are Only a Game: The Walrasian FixedSupply Conjecture Model, Contest Nash Equilibrium, and the Invariance Principle," Journal of Sports Economics, 2004, 5, 111-126.

Szymanski, S., and Késenne, S., "Competitive Balance and Gate Revenue Sharing in Team Sports," Journal of Industrial Economics, 2004, 52, 165-177.

Vrooman, J., "A General Theory of Professional Sports Leagues," Southern Economic Journal, 61, 4, 971-990.

Wright, J., “Optimal Card Payment Systems”, European Economic Review, 2003, 47, 587-612. 


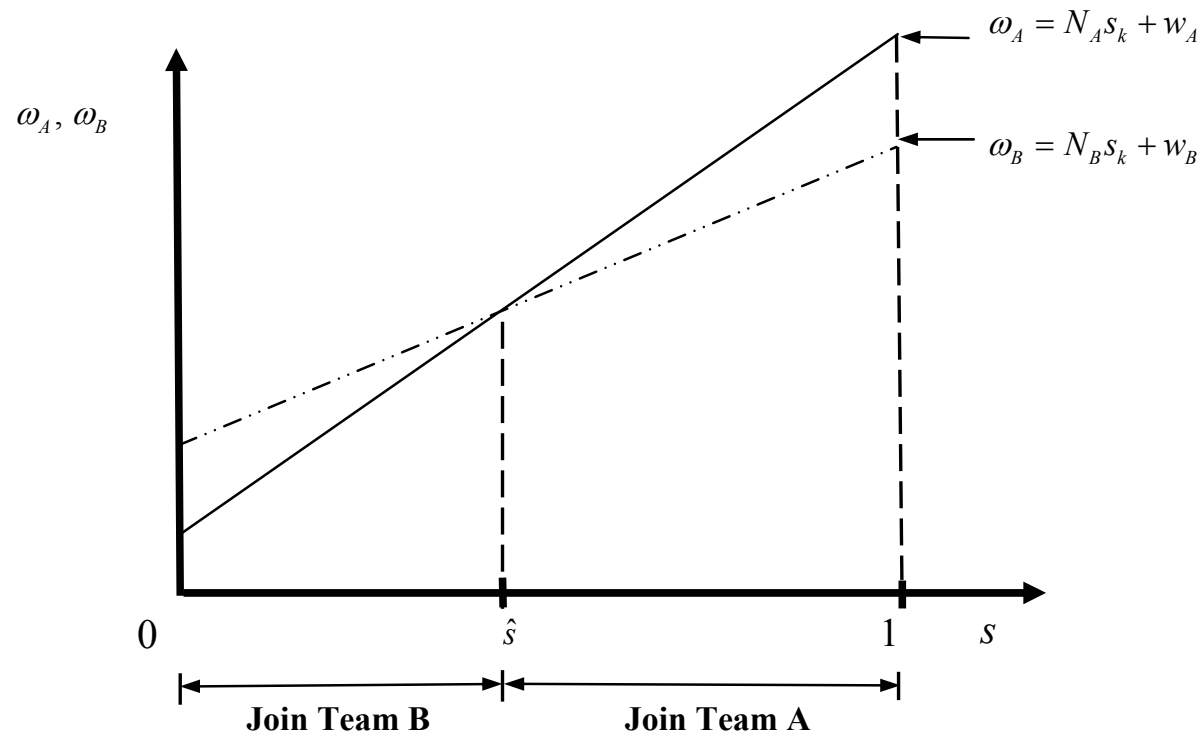

Figure 1. Talented players' choice

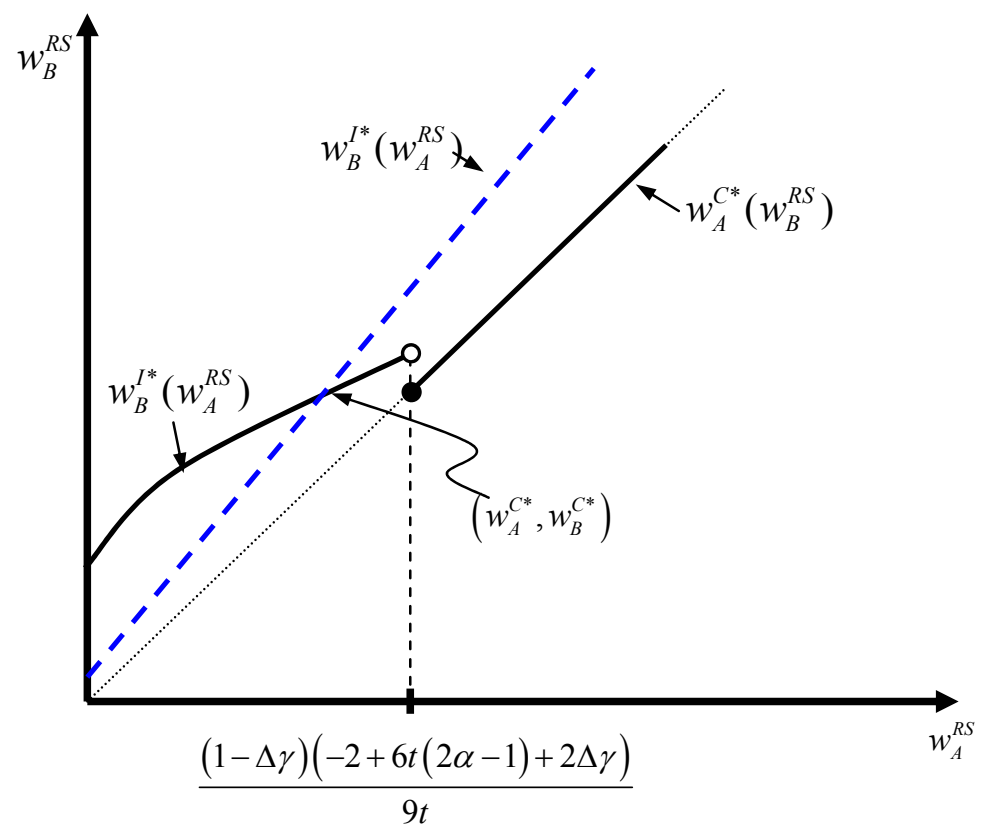

Figure 2. Alleviated imbalance outcome under configuration II 


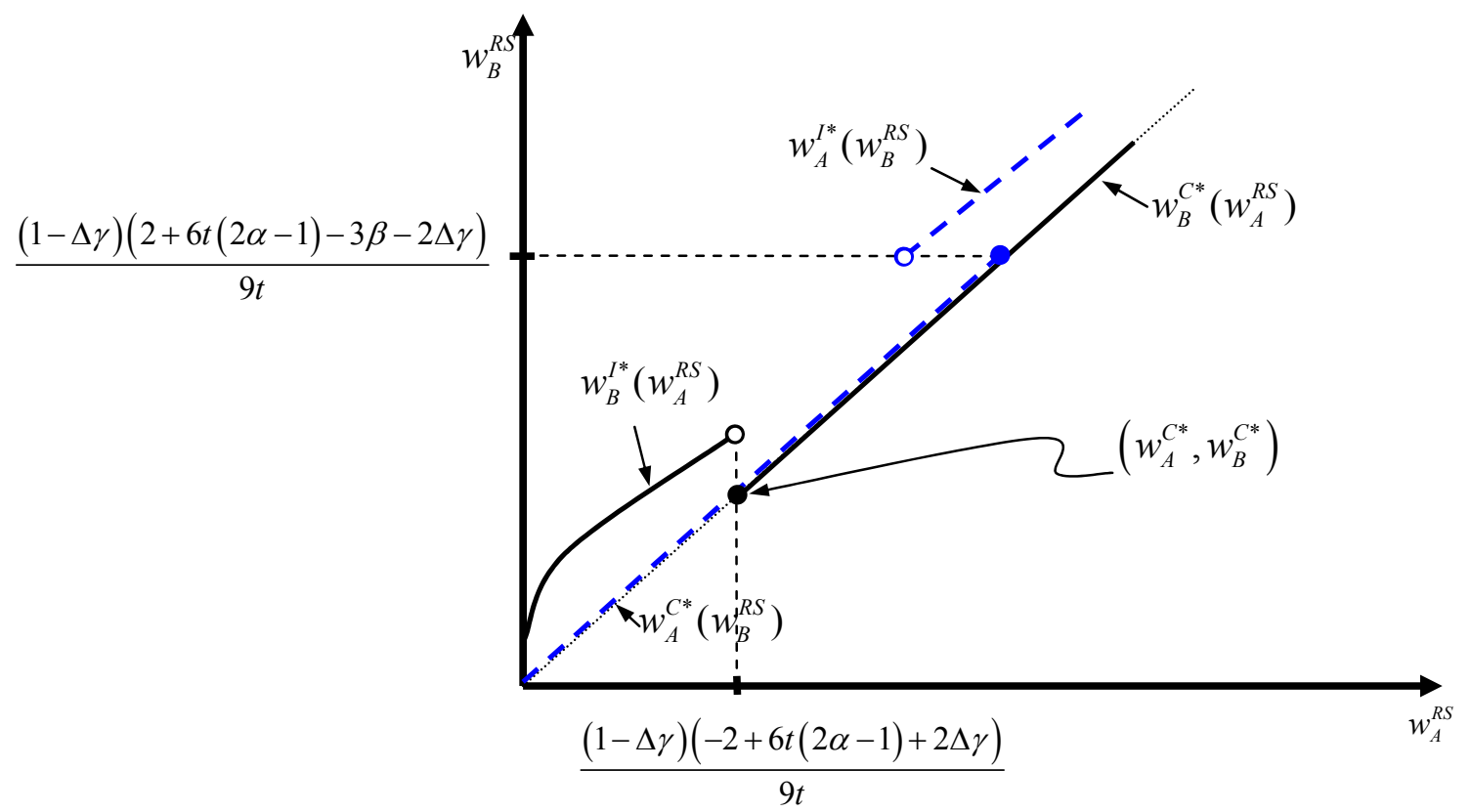

Figure 3. Imbalance Outcome under configuration III

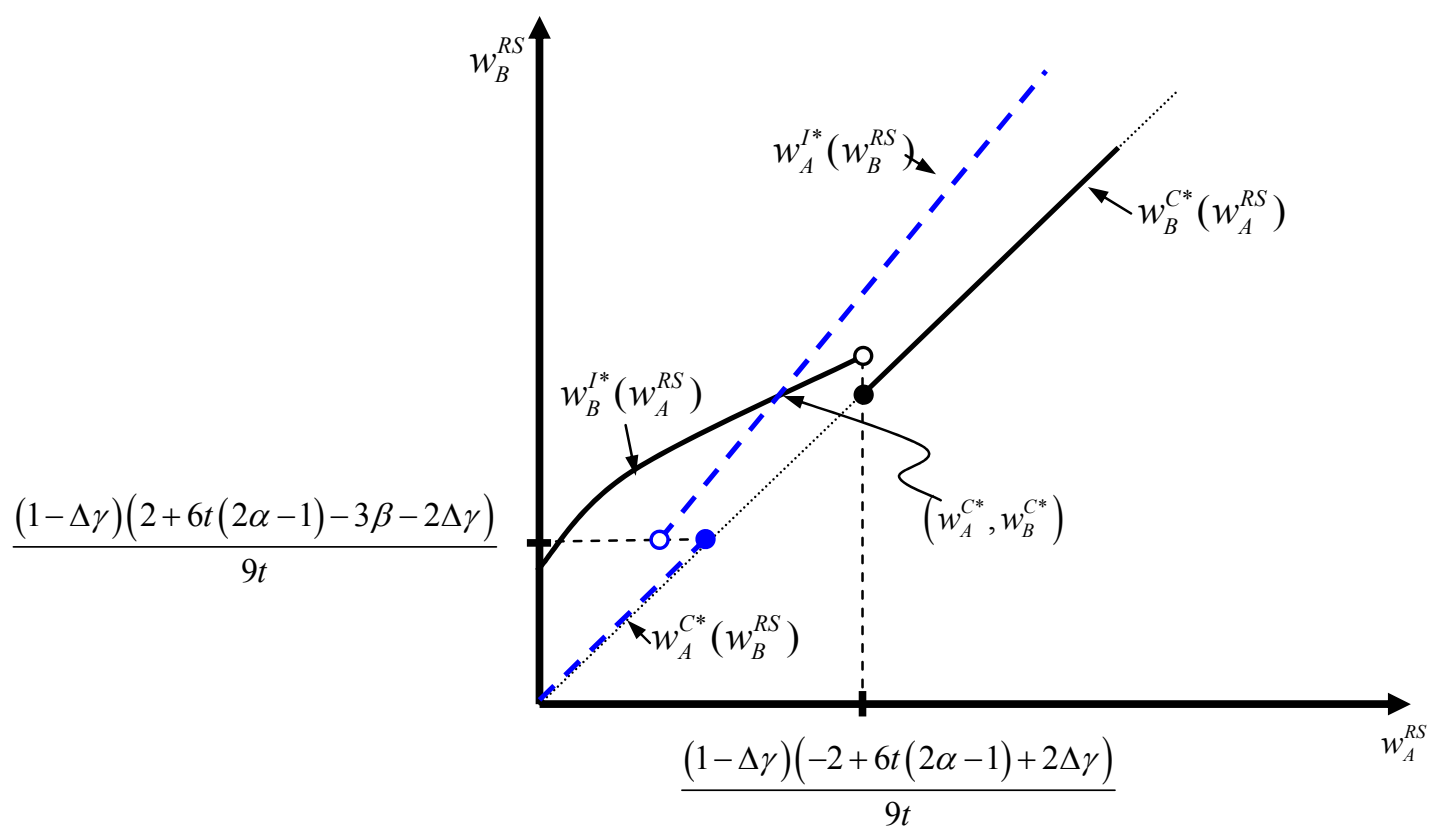

Figure 4. Alleviated imbalance outcome under configuration III 


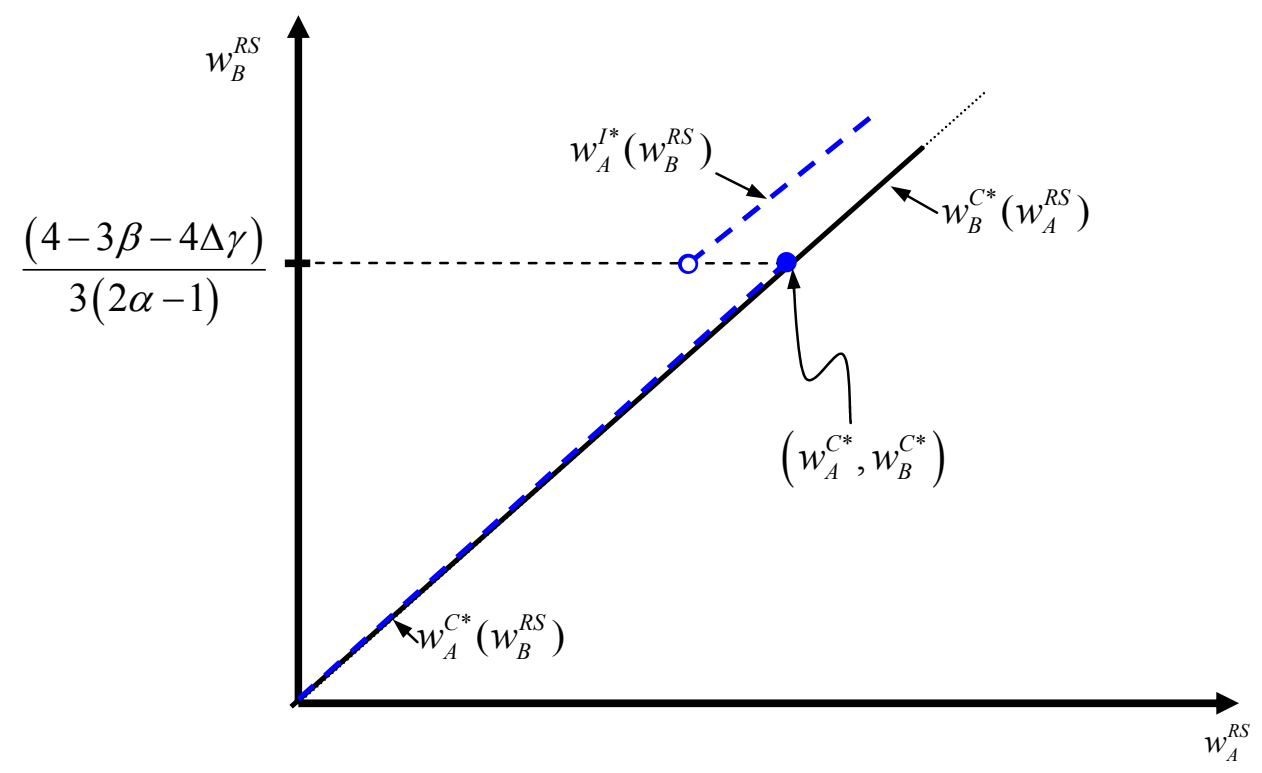

Figure 5. Imbalance Outcome under configuration IV

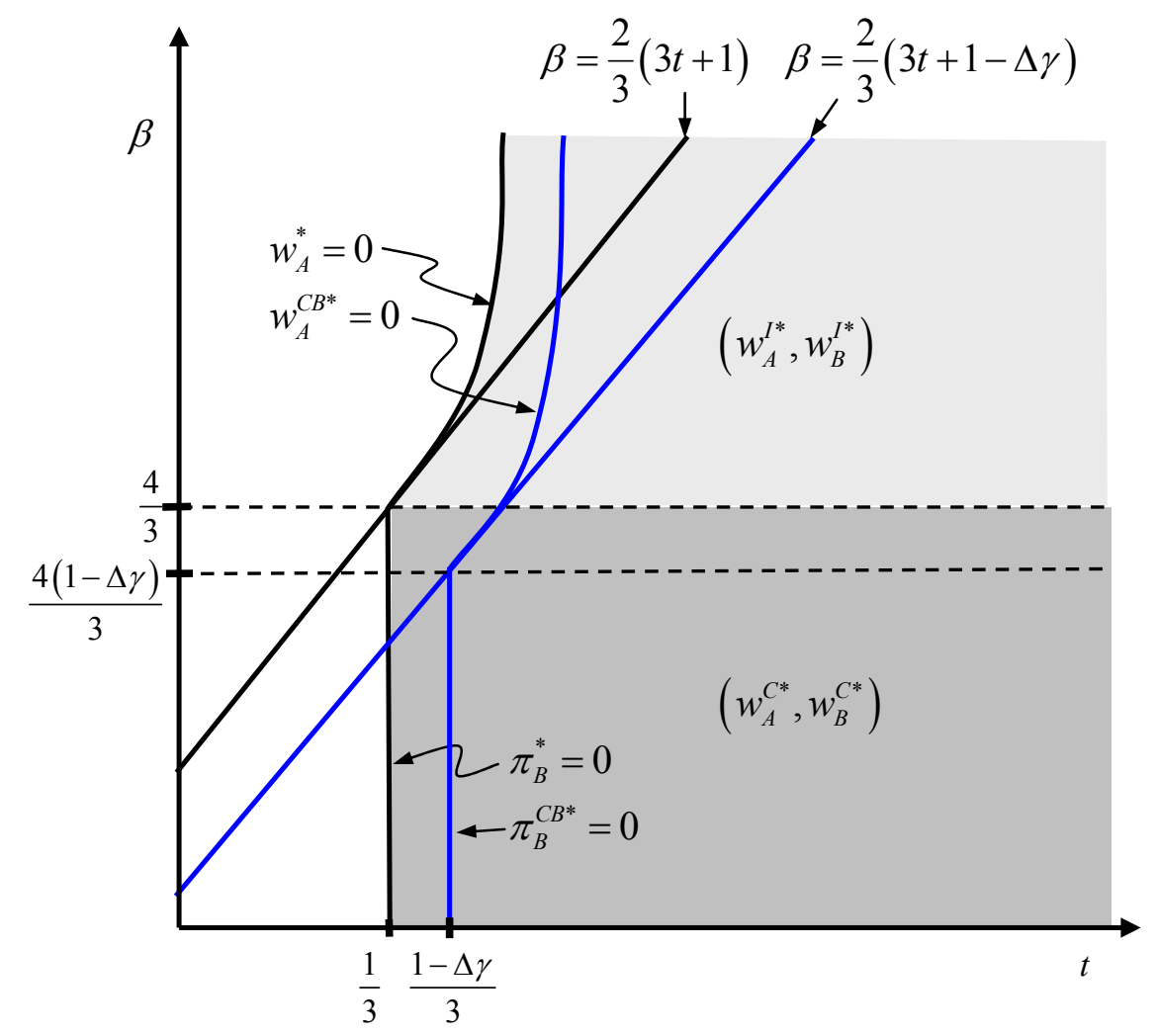

Figure 6. Comparison of equilibrium configurations between the basic model and the one with competitive balance effects in the case of $\gamma_{A}>\gamma_{B}$ 


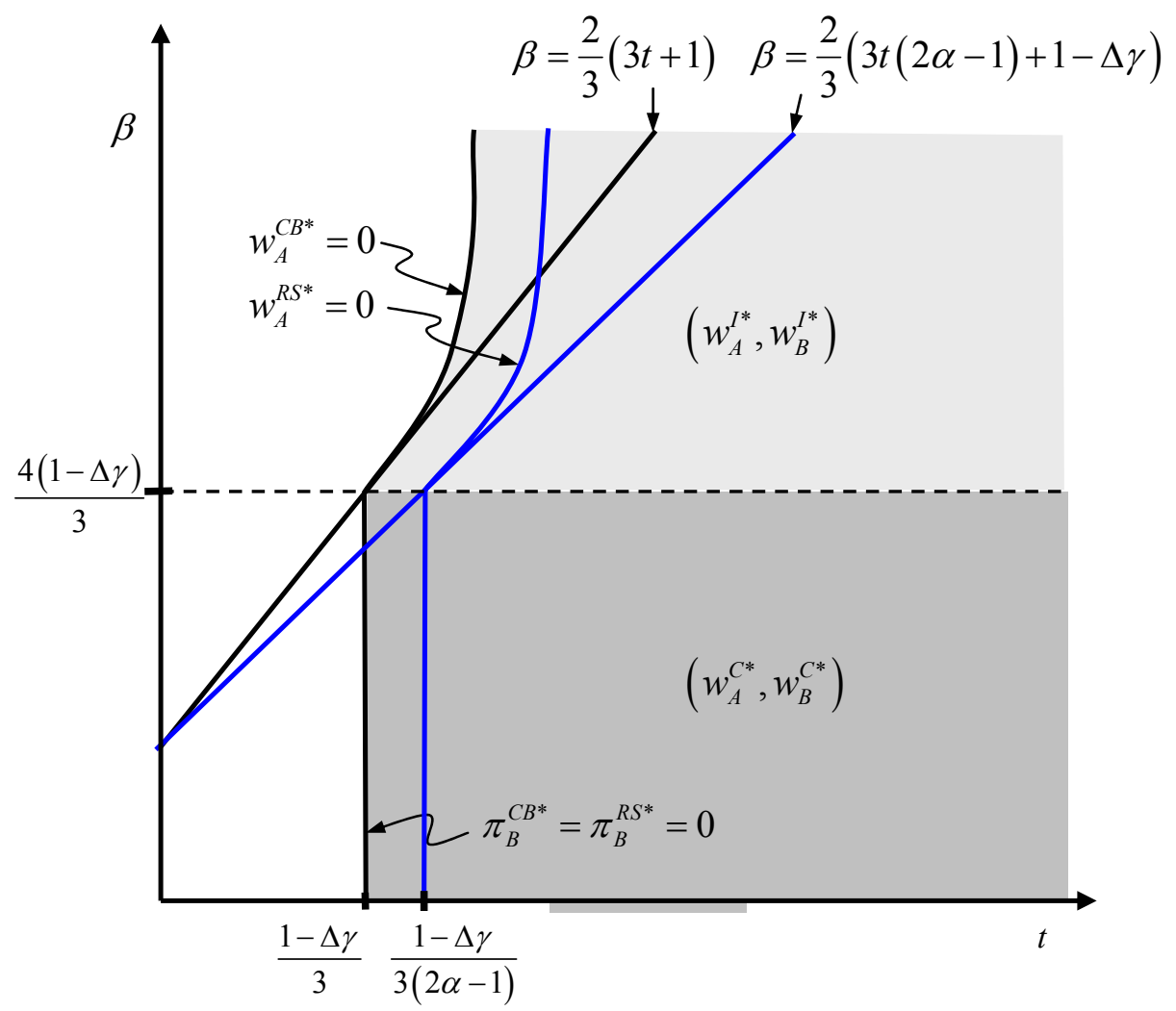

Figure 7. Comparison of equilibrium configurations between the extended model and the one with revenue sharing scheme 


\section{Appendix A}

Proof of proposition 3

Each team's best-response function, $w_{A}^{*}(\cdot)$ and $w_{B}^{*}(\cdot)$, has two segments. Therefore, we need to check the existence of pure strategy equilibria for the four following configurations;

1. Configuration I: $\beta>\frac{2}{3}(3 t(2 \alpha-1)+1-\Delta \gamma)$ and $t \leq \frac{1-\Delta \gamma}{3(2 \alpha-1)}$

2. Configuration II: $\beta>\frac{2}{3}(3 t(2 \alpha-1)+1-\Delta \gamma)$ and $t>\frac{1-\Delta \gamma}{3(2 \alpha-1)}$

3. Configuration III: $\beta \leq \frac{2}{3}(3 t(2 \alpha-1)+1-\Delta \gamma)$ and $t>\frac{1-\Delta \gamma}{3(2 \alpha-1)}$

4. Configuration IV: $\beta \leq \frac{2}{3}(3 t(2 \alpha-1)+1-\Delta \gamma)$ and $t \leq \frac{1-\Delta \gamma}{3(2 \alpha-1)}$

\section{Configuration I:}

In this configuration team A's best-response function is $w_{A}^{I^{*}}\left(w_{B}^{R S}\right)=w_{B}^{R S}-\frac{\beta(1-\Delta \gamma) \hat{s}_{A}^{R S}\left(1-2 \hat{s}_{A}^{R S}\right)}{3 t}$ with $\hat{s}_{A}^{R S}>0$ for any $w_{B}^{R S} \in[0, \infty]$ and $w_{B}^{C^{*}}\left(w_{A}^{R S}\right)=w_{A}^{R S}$ with $\hat{s}_{B}^{R S}=0$ for any $w_{A}^{R S} \in[0, \infty]$ for team B. The configuration $\left(w_{A}^{I^{*}}(\cdot), w_{B}^{C^{*}}(\cdot)\right)$ cannot be an equilibrium because $w_{A}^{I^{*}}<w_{B}^{C^{*}}$ and thus $w_{A}^{I^{*}}$ cannot be equal to $w_{B}^{R S}$.

\section{Configuration II:}

In this configuration team B's best-response function is discontinuous, thus has two segments as defined by equation (28), whereas team A has one continuous segment. The segment of $w_{B}^{C^{*}}(\cdot)$ has no equilibrium because $w_{A}^{I^{*}}<w_{B}^{C^{*}}$ and thus $w_{A}^{I^{*}}$ cannot be equal to $w_{B}^{R S}$. The other segment, where the configuration $\left(w_{A}^{I^{*}}(\cdot), w_{B}^{I^{*}}(\cdot)\right)$ has the solution which is shown in (2) of proposition 3, need a non-negative bidding constraint such as 
$\beta<\frac{1}{12}\left(-19+75 t(2 \alpha-1)-19 \Delta \gamma+\frac{1}{3} \sqrt{(225 t(2 \alpha-1)+57(1-\Delta \gamma))^{2}+576(1-\Delta \gamma)^{2}}\right)$

since $w_{A}^{I^{*}} \rightarrow 0$ as $t \rightarrow \frac{1-\Delta \gamma}{3(2 \alpha-1)}, \beta \rightarrow \frac{4(1-\Delta \gamma)}{3}$.

Configuration III:

In this configuration both teams' best-response functions defined by equations (27) and (28) respectively is discontinuous thus has two segments, in which the configuration $\left(w_{A}^{C^{*}}(\cdot), w_{B}^{C^{*}}(\cdot)\right)$ has equilibria if and only if $\frac{(1-\Delta \gamma)(2+6 t(2 \alpha-1)-3 \beta-2 \Delta \gamma)}{9 t} \geq \frac{(1-\Delta \gamma) 2(3 t(2 \alpha-1)-1+\Delta \gamma)}{9 t}$, which yields $\beta \leq \frac{4}{3}(1-\Delta \gamma)$. Indeed, solving the system $w_{A}=w_{A}^{C^{*}}\left(w_{B}\right)$ and $w_{B}=w_{B}^{C^{*}}\left(w_{A}\right)$, we easily find $w_{A}^{R S^{*}}=w_{B}^{R S^{*}} \in\left[\frac{(1-\Delta \gamma) 2(3 t(2 \alpha-1)-1+\Delta \gamma)}{9 t}, \frac{(1-\Delta \gamma)(2+6 t(2 \alpha-1)-3 \beta-2 \Delta \gamma)}{9 t}\right]$. Therefore, any wage offer belonging to the interval is a Nash equilibrium (see Figure 3). On the other hand, when $\beta>\frac{4}{3}(1-\Delta \gamma)$ we have equilibrium of $\hat{s}^{R S^{*}}, w_{A}^{I^{*}}$ and $w_{B}^{I^{*}}$ by solving system of equations (19a), (19b), (26a), and (26b) with $\hat{s}_{A}^{R S}=\hat{s}_{B}^{R S}=\hat{s}^{R S}$. We also verify where $w_{A}^{I^{*}}$, the intersection of $\left(w_{A}^{I^{*}}(\cdot), w_{B}^{I^{*}}(\cdot)\right)$, is located as $\frac{(1-\Delta \gamma)(2+6 t(2 \alpha-1)-3 \beta-2 \Delta \gamma)}{9 t}<w_{A}^{I^{*}}<\frac{(1-\Delta \gamma) 2(3 t(2 \alpha-1)-1+\Delta \gamma)}{9 t}$ if $\beta>\frac{4}{3}(1-\Delta \gamma)$ (see Figure 4$)$.

\section{Configuration IV:}

In this configuration team A's best response function is defined by equation (27) and $w_{B}^{C^{*}}\left(w_{A}^{R S}\right)=w_{A}^{R S}$ with $\hat{s}_{B}^{R S}=0$ for any $w_{A}^{R S} \in[0, \infty]$ for team B. The configuration $\left(w_{A}^{C^{*}}(\cdot), w_{B}^{C^{*}}(\cdot)\right)$ has equilibria at $w_{A}^{R S}=w_{B}^{R S} \in\left[0, \frac{(1-\Delta \gamma)(2+6 t(2 \alpha-1)-3 \beta-2 \Delta \gamma)}{9 t}\right]$ 
with $\hat{S}^{R S^{*}}=0$. However, applying the non-negative profit constraint rules out some of equilibria in this configuration since team B's profit equals $\frac{(3 t-(1-\Delta \gamma))^{2}}{18 t}$ with perfect imbalance solution, $\hat{s}^{R S^{*}}=0$, which yields $t \geq \frac{1-\Delta \gamma}{3}$. Therefore, the configuration $\left(w_{A}^{C^{*}}(\cdot), w_{B}^{C^{*}}(\cdot)\right)$ has equilibria at $t \in\left[\frac{1-\Delta \gamma}{3}, \frac{1-\Delta \gamma}{3(2 \alpha-1)}\right]$. 


\section{Appendix B}

Proof of proposition 4

The profit function (25a) and (25b) can be written as

$$
\begin{aligned}
& \pi_{A}^{R S}=\alpha R_{A}^{R S}\left(\theta_{A}\left(s_{\hat{A}}^{\underline{M P}}\right), \theta_{B}\left(s_{A}^{R S}\right)\right)+(1-\alpha) R_{B}^{R S}\left(\theta_{A}\left(s_{\hat{A}}^{\underline{M P}}\right), \theta_{B}\left(s_{A}^{R S}\right)\right)-w_{A}\left(1-s_{A}^{R S}\right)(\mathrm{B} 1), \\
& \pi_{B}^{R S}=\alpha R_{B}^{R S}\left(\theta_{A}\left(s_{\hat{B}}^{2 R S}\right), \theta_{B}\left(s_{B}^{R S}\right)\right)+(1-\alpha) R_{A}^{R S}\left(\theta_{A}\left(s_{\hat{B}}^{2 P S}\right), \theta_{B}\left(s_{B}^{R S}\right)\right)-w_{B}\left(s_{B}^{R S}\right) \text { (B2). }
\end{aligned}
$$

The derivatives of (B1) and (B2) are:

$$
\begin{aligned}
& \frac{d \pi_{A}^{R S}}{d \hat{s}_{A}^{R S}}=\alpha\left[R_{A A} \frac{d \theta_{A}}{d \hat{s}_{A}^{R S}}+R_{A B} \frac{d \theta_{B}}{d \hat{s}_{A}^{R S}}\right]+(1-\alpha)\left[R_{B A} \frac{d \theta_{A}}{d \hat{s}_{A}^{R S}}+R_{B B} \frac{d \theta_{B}}{d \hat{s}_{A}^{R S}}\right]+w_{A}=0 \\
& \frac{d \pi_{B}^{R S}}{d \hat{s}_{B}^{R S}}=\alpha\left[R_{B A} \frac{d \theta_{A}}{d \hat{s}_{B}^{R S}}+R_{B B} \frac{d \theta_{B}}{d \hat{s}_{B}^{R S}}\right]+(1-\alpha)\left[R_{A A} \frac{d \theta_{A}}{d \hat{s}_{B}^{R S}}+R_{A B} \frac{d \theta_{B}}{d \hat{s}_{B}^{R S}}\right]-w_{B}=0
\end{aligned}
$$

where $R_{A j}=\frac{\partial R_{A}}{\partial \theta_{j}}$ and $R_{B j}=\frac{\partial R_{A}}{\partial \theta_{j}}$ with $j=A, B$.

With adding up condition $\frac{d \theta_{j}}{d \hat{s}_{j}^{R S}}+\frac{d \theta_{-j}}{d \hat{s}_{j}^{R S}}=1$ and applying the one-to-one relationship between $\theta_{j}$ and $\hat{s}_{j}$ such as $\frac{d \theta_{A}}{d \hat{s}_{A}^{R S}}=-1$ and $\frac{d \theta_{B}}{d \hat{s}_{B}^{R S}}=1$ equations (B3) and (B4) become

$$
\begin{aligned}
& -\alpha R_{A A}+\alpha R_{A B}-(1-\alpha) R_{B A}+(1-\alpha) R_{B B}+w_{A}=0 \\
& -\alpha R_{B A}+\alpha R_{B B}-(1-\alpha) R_{A A}+(1-\alpha) R_{A B}-w_{B}=0
\end{aligned}
$$

Taking the difference of equations (B5) and (B6) gives us

$$
-R_{A A}+R_{A B}+\frac{w_{A}}{(2 \alpha-1)}=R_{B B}-R_{B A}-\frac{w_{B}}{(2 \alpha-1)}
$$

which confirms that an increase in $\alpha$ reduces wage offers, but does not affect marginal revenues which means that the invariance principle holds. 